\title{
ELLIPSOMETRY OF METAL DEPOSITION
}

\author{
W. VISSCHER and A. P. COX \\ Laboratory of Inorganic Chemistry and Catalysis, Eindhoven University of Technology, P.O. Box 513,
} 5600 MB Eindhoven, The Netherlands

(Received 30 January 1992)

\begin{abstract}
The initial stages during galvanic deposition were monitored by ellipsometry in combination with cyclic voltammetry for the growth of $\mathrm{Bi}, \mathrm{Cu}$ and $\mathrm{Ge}$ films on polycrystalline $\mathrm{Au}, \mathrm{Pd}$ and $\mathrm{Pt}$ substrates. The upd of $\mathrm{Bi}$ on $\mathrm{Au}$, of $\mathrm{Ge}$ on $\mathrm{Pt}$ and of $\mathrm{Cu}$ on $\mathrm{Au}$ could be detected ellipsometrically but not for $\mathrm{Bi}$ on Pd or Pt. The refractive index of the upd film of $\mathrm{Bi}$ on Au changes with increasing coverage. The bulk deposit film of $\mathrm{Bi}$ on $\mathrm{Au}$ and of $\mathrm{Cu}$ on $\mathrm{Au}$ grows at constant refractive index.
\end{abstract}

Key words: upd, metal deposition, ellipsometry, refractive index, cyclic voltammetry.

\section{INTRODUCTION}

The initial stages of metal deposition on a foreign metal substrate often involve the formation of a (sub)monolayer, which differs from the bulk layer as is indicated by its potential shift to more positive potentials with respect to the Nernst potential. This shift depends on the difference in work function of depositing metal and substrate metal and is affected by the crystallographic orientation of the substrate[1-5]. Adsorption of anions can induce lateral interaction effects and so cause a decrease in the $u p d$ shift, furthermore the upd can be influenced by an oxide film. The upd of metals can take place with partial charge transfer depending on the magnitude of the difference in electronegativity. Parameters which determine the structure of the upd layer are: the ratio of the atomic radii of the adsorbing metal and the substrate metal; the structure of the substrate itself and the adsorptive and lateral interactions of the adsorbate. In principle the accommodation of the upd layer on the substrate can be, in the case of $1 / 1$ adsorption, epitaxial for $r_{\text {dep }}<r_{\text {substr }}$ and for $1 / n$ or multisite adsorption, hexagonal close packed for $r_{\text {dep }}>r_{\text {substr }}$; in the latter case it is generally assumed that some superlattice structures are formed which are transformed to higher order phase transition with increasing coverage.

Bulk electrocrystallization proceeds via nucleation and growth; if an upd layer has been formed, the nucleation process takes place within the adsorption layer and involves a reorganization. The adsorbed layer in fact provides a modified substrate for the bulk metal deposition[6].

The presence of an upd layer also influences the electrocatalytic properties of the substrate by providing different acting sites and thus operating as a bifunctional catalyst or by modifying the electronic properties of the substrate. The activity of adatomelectrodes for oxidation of organic fuels is higher for oxygen adsorbing adatoms than for non oxygen adsorbing adatoms[7].

Optical reflection techniques can give information on the nature of the upd layer. These techniques are very sensitive in situ methods and can be used to monitor the substrate during deposition and/or dissolution of the adsorbate. Also the onset of bulk deposition can be measured up to some $10 \mathrm{~nm}$, depending on the system; this can indicate whether the growth proceeds homogeneously or not. Determination of the true optical constants, however, can be difficult if the substrate properties are altered by the adsorbing species.

The galvanic deposition process was studied with cyclic voltammetry and ellipsometry for growth of $\mathrm{Bi}$, $\mathrm{Cu}$ and $\mathrm{Ge}$ films on polycrystalline $\mathrm{Au}, \mathrm{Pt}$ and $\mathrm{Pd}$ substrates. With $r(\mathrm{Ge})<r(\mathrm{Pt}) ; r(\mathrm{Bi})>r(\mathrm{Au}, \mathrm{Pd}, \mathrm{Pt})$ and $r(\mathrm{Cu})<r(\mathrm{Au})$ an epitaxial layer is expected at full coverage for upd of $\mathrm{Cu}$ on $\mathrm{Au}$ and $\mathrm{Ge}$ on $\mathrm{Pt}$ and a hexagonal close packed layer for $\mathrm{Bi}$ on $\mathrm{Au}$, $\mathrm{Pd}$ and $\mathrm{Pt}$.

\section{EXPERIMENTAL}

All experiments were carried out in a cylindrical Teflon cell with windows arranged for an angle of incidence of $70^{\circ}$ at the substrate. The substrate electrodes were discs (area $0.5 \mathrm{~cm}^{2}$ ) of Pt, Au and Pd; before each measurement they were polished with $0.05 \mu \mathrm{m}$ alumina. The reference electrode is mercurymercurous sulphate (mse), $0.65 \mathrm{~V} v s$ nhe, the counter electrode is a Pt foil.

The electrolyte, $0.5 \mathrm{M} \mathrm{H}_{2} \mathrm{SO}_{4}$ or $1 \mathrm{M} \mathrm{HClO}_{4}$ with $x \mathrm{M} \mathrm{Bi}, \mathrm{Cu}$ or $\mathrm{Ge}$ salts were prepared from AnalaR Chemicals and doubly distilled water and were deaerated with $\mathbf{N}_{2}$.

The equipment consisted of a Wenking potentiostat POS 73 and an automatic ellipsometer, Rudolph RR 2200, with a tungsten iodine light source and monochromatic filters.

\section{RESULTS AND DISCUSSION}

\section{Upd of $\mathrm{Bi}$ on $\mathrm{Au}$}

The upd of $\mathrm{Bi}$ on $\mathrm{Au}$ in $1 \mathrm{M} \mathrm{HClO}_{4}+1 \mathrm{mM}$ $\mathrm{Bi}\left(\mathrm{NO}_{3}\right)_{3}$ is characterized by a number of peaks in the voltammogram; Fig. 1 represents the diagram at a 
scan rate of $10 \mathrm{mV} \mathrm{s}^{-1}$. The optical diagram, Fig. 2 , shows inflections of $\Delta$ at $-200,-300$ and $-410 \mathrm{mV}$ during the cathodic scan. The total coulometric charge up to $-410 \mathrm{mV}$ corresponds to a monolayer. Due to the relatively small differences in Pauling's electronegativity, the adatoms are completely discharged and covalently bound[8]. For the Bi/Au system the adsorbed layer will be hexagonal close packed. The results indicate that the upd layer changes during deposition; calculation of the refractive index for the film at these potentials yields increasing $n, k$ values with coverage. The data are summarized in Table 1 ; the high $k$ value is typical for the metallic character of the upd film. Reflectivity measurements[9] also indicate a change during the formation of the upd layer. Similar behaviour has been found for the upd of $\mathrm{Pb}$ on $\mathrm{Au}[10,11]$.

\section{Upd of $\mathrm{Bi}$ on $\mathrm{Pd}$ and $\mathrm{Pt}$}

In the system $\mathrm{Bi} / \mathrm{Pd}$ and $\mathrm{Bi} / \mathrm{Pt}$ the presence of an oxide film interferes with upd. Figure 3 shows the

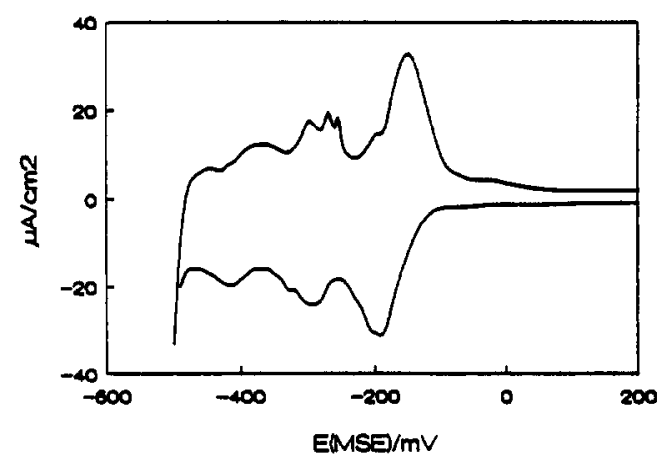

Fig. 1. Voltammogram of $\mathrm{Au}$ in $1 \mathrm{M} \mathrm{HClO}_{4}+1 \mathrm{mM}$ $\mathrm{Bi}\left(\mathrm{NO}_{3}\right)_{3}$; scan rate, $10 \mathrm{mV} \mathrm{s}^{-1}$.

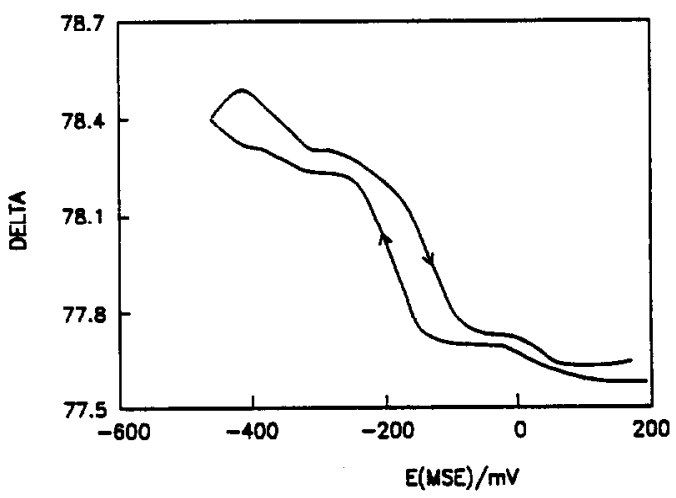

Fig. 2. Ellipsometric change during potential scan of $\mathrm{Au}$ in $1 \mathrm{M} \mathrm{HClO}_{4}+1 \mathrm{mM} \mathrm{Bi}\left(\mathrm{NO}_{3}\right)_{3}$; wavelength, $546.1 \mathrm{~nm}$; scan rate, $10 \mathrm{mV} \mathrm{s}^{-1}$.

Table 1. Change of refractive index of $\mathrm{Bi}$ upd film on $\mathrm{Au}$ at indicated potentials in $1 \mathrm{M}$ $\mathrm{HClO}_{4}+1 \mathrm{mM} \quad \mathrm{Bi}\left(\mathrm{NO}_{3}\right)_{3} ; \quad$ wavelength, $546.1 \mathrm{~nm}$

\begin{tabular}{llll}
\hline Peak $/ \mathrm{mV}$ & $\boldsymbol{\theta}$ & $\boldsymbol{n}$ & $\boldsymbol{k}$ \\
\hline-200 & 0.52 & 0.83 & 4.77 \\
-300 & 0.85 & 1.15 & 4.30 \\
-410 & 1.0 & 1.27 & 4.25 \\
\hline
\end{tabular}

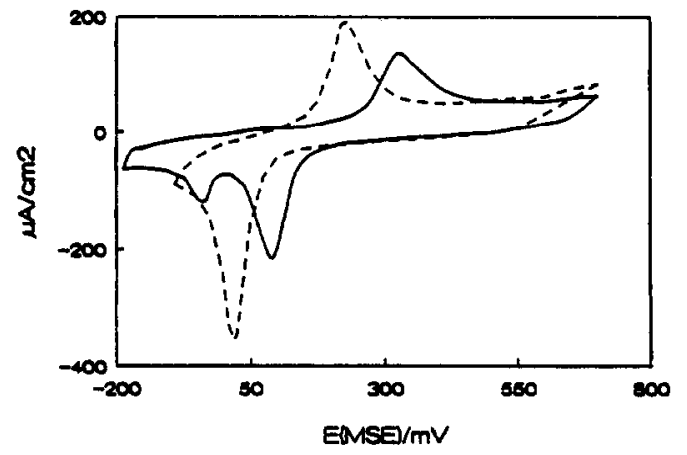

Fig. 3. Voltammogram of $\mathrm{Pd}$ in $0.5 \mathrm{M} \mathrm{H}_{2} \mathrm{SO}_{4}+0.2 \mathrm{mM}$ $\mathrm{Bi}\left(\mathrm{NO}_{3}\right)_{3}$ (dashed line) and in $1 \mathrm{M} \mathrm{HClO} 4+0.7 \mathrm{mM}$ $\mathrm{Bi}\left(\mathrm{NO}_{3}\right)_{3}$ (full line); scan rate, $20 \mathrm{mV} \mathrm{s}^{-1}$.

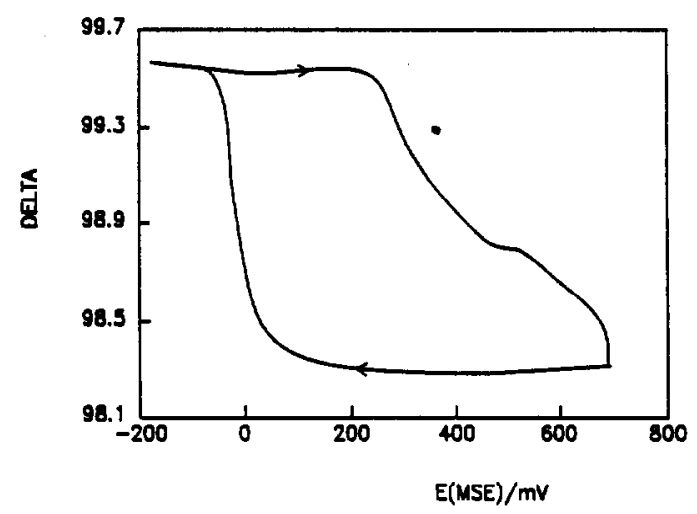

Fig. 4. Ellipsometric change during potential scan of $\mathrm{Pd} / \mathrm{Bi}$ system in $0.5 \mathrm{M} \mathrm{H}_{2} \mathrm{SO}_{4}$; scan rate, $20 \mathrm{mV} \mathrm{s}^{-1}$; wavelength, $546.1 \mathrm{~nm}$.



Fig. S. Ellipsometric change during potential scan of $\mathrm{Pd} / \mathrm{Bi}$ system in $1 \mathrm{M} \mathrm{HClO}_{4}$; scan rate, $20 \mathrm{mV} \mathrm{s}^{-1}$; wavelength, $546.1 \mathrm{~nm}$.

voltammogram for the upd of $\mathrm{Bi}$ on $\mathrm{Pd}$ : in $0.5 \mathrm{M}$ $\mathrm{H}_{2} \mathrm{SO}_{4}$ the upd is detected only in the anodic scan; in $1 \mathrm{M} \mathrm{HClO}$, the oxide peak is shifted to higher potential and a $\mathrm{Bi}$ upd peak is now also noticed in the cathodic voltammogram. The $\mathrm{Bi}$ upd layer is indirectly detected in the optical potential scans of Figs 4 and 5: its presence prevents the oxidation of $\mathrm{Pd}$; once $\mathrm{Bi}$ is oxidized and dissolved, the substrate oxidation starts as indicated by the kink in the anodic scan at $230 \mathrm{mV}\left(\mathrm{H}_{2} \mathrm{SO}_{4}\right)$ and $300 \mathrm{mV}\left(\mathrm{HClO}_{4}\right)$ respectively. 
The $\mathrm{Bi} / \mathrm{Pt}$ system shows similar behaviour in $1 \mathrm{M}$ $\mathrm{HClO}_{4}$ : the cathodic voltammogram reveals a small peak following the reduction of the platinum oxide and a steep peak at $220 \mathrm{mV}$ in the reverse scan, in agreement with Refs $[9,12,13]$. The optical response (Fig. 6) indicates the disappearance of the upd film and the start of oxidation in the anodic scan at about $350 \mathrm{mV}$. Cadle and Bruckenstein[12] concluded that the initial $\mathrm{Bi}$ (III) reduction occurs simultaneously with the reduction of the $\mathrm{Pt}$ oxide; $\mathrm{Bi}(0)$ is only partially removed in the anodic scan.

The $\mathrm{Bi}$ upd layer on $\mathrm{Pd}$ and $\mathrm{Pt}$ does not reach full coverage[12,13]; the ellipsometric results imply that the resulting optical constants of the film are close to those of the substrate. These results differ somewhat from reflectivity measurements of Takamura et al.[9] for $\mathrm{Bi} / \mathrm{Pd}$ and $\mathrm{Bi} / \mathrm{Pt}$; this may be due to a difference in potential range and scan rate.

\section{Upd of $\mathrm{Ge}$ on $\mathrm{Pt}$}

Figures 7 and 8 show the voltammogram and optical response in the potential range 700 to $-650 \mathrm{mV}$ for $\mathrm{Pt}$ in $0.5 \mathrm{M} \mathrm{H}_{2} \mathrm{SO}_{4}+1 \mathrm{mM} \mathrm{GeO}_{2}$. Both the onset of upd of $\mathrm{Ge}$ and the dissolution are clearly observed by the change of $\Delta$ at $-350 \mathrm{mV}$ in the cathodic scan and at $-30 \mathrm{mV}$ in the anodic scan (Fig. 8).

At potentials $<-600 \mathrm{mV}$ bulk and alloy formation occurs. With repeated scanning the electrode

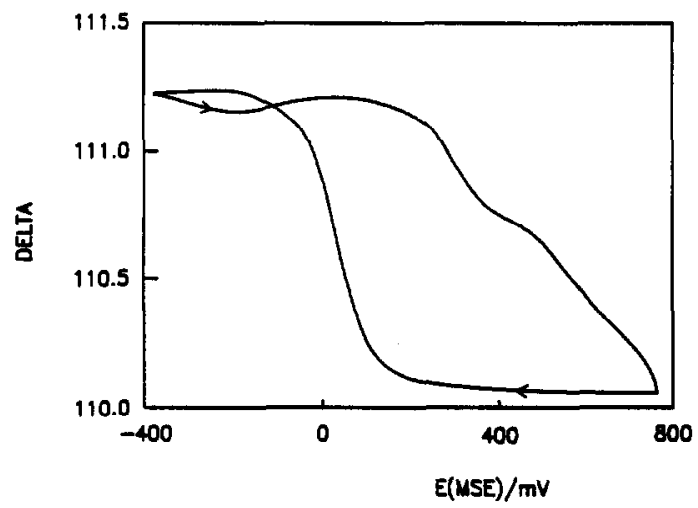

Fig. 6. Ellipsometric change during potential scan of $\mathrm{Pt}$ in $1 \mathrm{M} \mathrm{HClO}_{4}+1 \mathrm{mM} \mathrm{Bi}\left(\mathrm{NO}_{3}\right)_{3}$; scan rate, $20 \mathrm{mV} \mathrm{s}^{-1}$; wavelength, $546.1 \mathrm{~nm}$.

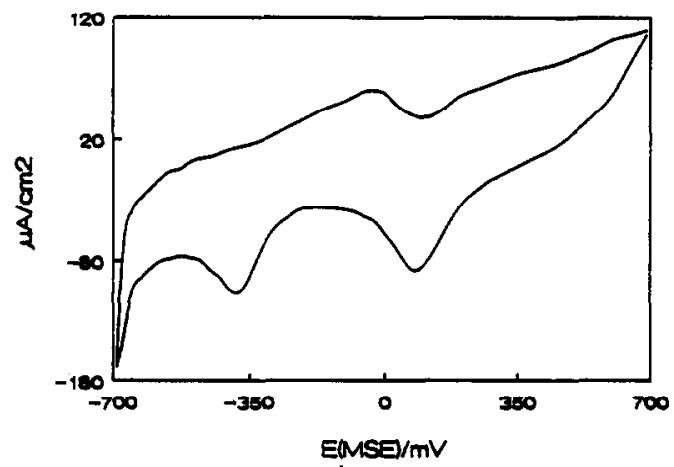

Fig. 7. Voltammogram of $\mathrm{Pt}$ in $0.5 \mathrm{M} \mathrm{H}_{2} \mathrm{SO}_{4}+1 \mathrm{mM} \mathrm{GeO}_{2}$; scan rate, $20 \mathrm{mV} \mathrm{s}^{-1}$

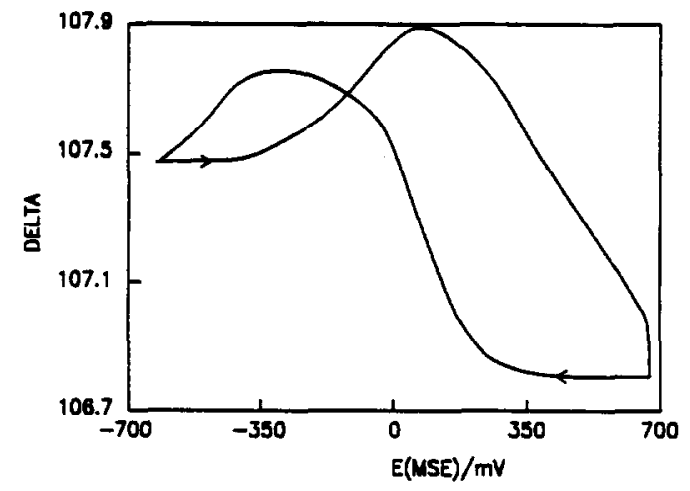

Fig. 8. Ellipsometric change during potential scan of $\mathrm{Pt}$ in $0.5 \mathrm{M} \mathrm{H}_{2} \mathrm{SO}_{4}+1 \mathrm{mM} \mathrm{GeO}_{2}$; scan rate, $5 \mathrm{mV} \mathrm{s}^{-1}$; wavelength, $546.1 \mathrm{~nm}$.

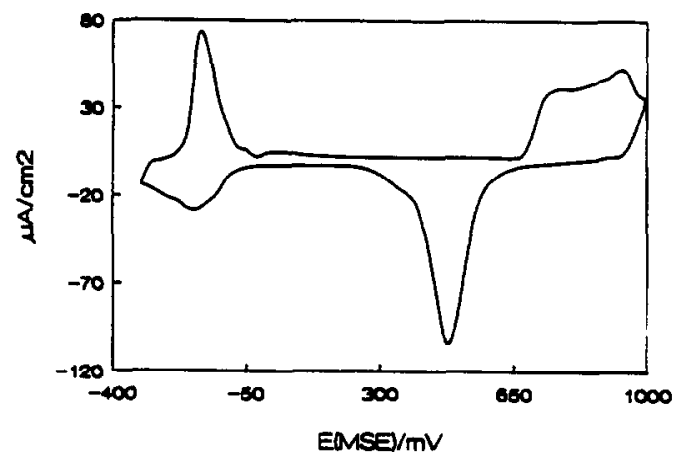

Fig. 9. Voltammogram of $\mathrm{Au}$ in $0.5 \mathrm{M} \mathrm{H}_{2} \mathrm{SO}_{4}+1 \mathrm{mM}$ $\mathrm{CuSO}_{4} ;$ scan rate, $200 \mathrm{mV} \mathrm{s}^{-1}$.

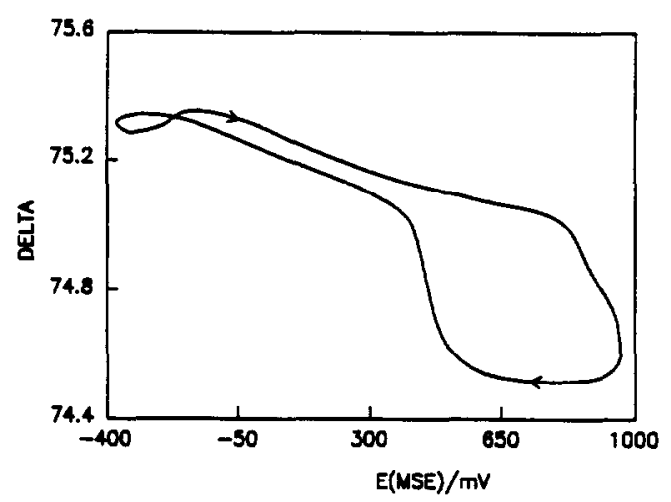

Fig. 10. Ellipsometric change during potential scan of $\mathrm{Cu} / \mathrm{Au}$ system; scan rate, $20 \mathrm{mV} \mathrm{s}^{-1}$; wavelength, $546.1 \mathrm{~nm}$.

becomes more active. Furuya and Motoo[14] have shown that the $\mathrm{Ge}$ adatoms adsorb oxygen in the potential region corresponding with the double layer region. Further evaluation of the data was therefore not performed.

\section{Upd of $\mathrm{Cu}$ on $\mathrm{Au}$}

The upd of $\mathrm{Cu}$ on $\mathrm{Au}$ in $0.5 \mathrm{M} \mathrm{H}_{2} \mathrm{SO}_{4}+1 \mathrm{mM}$ $\mathrm{CuSO}_{4}$ corresponds with a monolayer and the voltammogram (Fig. 9) shows a distinct peak, as was investigated by Lorenz et al.[15]. The optical changes, however, were found to be very small (Fig. 10); this was observed at all wavelengths in the range 




Fig. 11. Ellipsometric change during potential scan $(20 \mathrm{mV}$ $\mathrm{s}^{-1}$ ) with onset of bulk deposition of $\mathrm{Cu}$ on $\mathrm{Au}$; wavelength, $546.1 \mathrm{~nm}$.

$450-650 \mathrm{~nm}$ and indicates that the optical constants of the upd layer are close to the values of the substrate. Reflectivity measurements also reveal only small effects $[9,16]$.

\section{Bulk deposition of $\mathrm{Cu}$ on $\mathrm{Au}$}

The onset of bulk deposition of $\mathrm{Cu}$ on $\mathrm{Au}$ is observed as a steep change in the optical diagram during potential scan, Fig. 11. The results, obtained at 546.1 and $450 \mathrm{~nm}$, for potentials -500 to $-800 \mathrm{mV}$ are given in Table 2; the data show a constant refractive index for layers with thickness up to $6 \mathrm{~nm}$. The same values were found for deposition of $\mathrm{Cu}$ on $\mathrm{Pt}[11]$, and agree with literature data for bulk $\mathrm{Cu}[17]$.

\section{Bulk deposition of $\mathrm{Bi}$ on $\mathrm{Au}, \mathrm{Pt}$ and $\mathrm{Pd}$}

Deposition of $\mathrm{Bi}$ on $\mathrm{Au}$ was followed with time at constant current of $0.1 \mathrm{~mA} \mathrm{~cm}{ }^{-2}$ in $1 \mathrm{M} \mathrm{HClO}_{4}+$ $2 \mathrm{mM} \mathrm{Bi}\left(\mathrm{NO}_{3}\right)_{3}$; the optical data are plotted as a $\Psi-\Delta$ graph in Fig. 12. The full line represents calculated data for film growth with refractive index $n=1.18$ and $k=1.85$ at $546.1 \mathrm{~nm}$. The results imply that the growth proceeds homogeneously to about $120 \AA$.

The deposition of a Bi film onto Pd or Pt does not appear to grow at constant refractive index; measurements at constant current or potential indicate an initially varying composition. The refractive index measured for a bulk layer deposit of about $120 \mathrm{mC}$ $\mathrm{cm}^{-2}$ is for Bi on Pt: $n=1.22 ; k=1.91$; for $\mathrm{Bi}$ on Pd: $n=1.76 ; k=3.17$.

The refractive index values of $\mathrm{Bi}$ on $\mathrm{Au}$ and on $\mathrm{Pt}$ are the same; for $\mathrm{Bi}$ on $\mathrm{Pd}$ a higher $n, k$ value is obtained. This might indicate some alloy formation as well[12]. Literature data for $\mathrm{Bi}$ are scarce and depend strongly on the crystallographic orientation[17].

Table 2. Refractive index and thickness of $\mathrm{Cu}$ film deposited on $\mathrm{Au}$ in $1 \mathrm{M} \mathrm{HClO}_{4}+1 \mathrm{mM} \mathrm{CuSO}{ }_{4}$ during potential scanning in the potential range -500 to $-800 \mathrm{mV}$

\begin{tabular}{lcccc}
\hline & \multicolumn{2}{c}{$\lambda=546.1 \mathrm{~nm}$} & \multicolumn{2}{c}{$\lambda=450 \mathrm{~nm}$} \\
Thickness $/ \AA$ & $n$ & $k$ & $n$ & $k$ \\
\hline 8 & 0.70 & 2.25 & & \\
25 & & & 1.00 & 2.10 \\
33 & 0.69 & 2.05 & & \\
44 & 0.69 & 2.20 & 1.02 & 2.05 \\
54 & & & 1.05 & 2.07 \\
58 & 0.70 & 2.30 & & \\
\hline
\end{tabular}

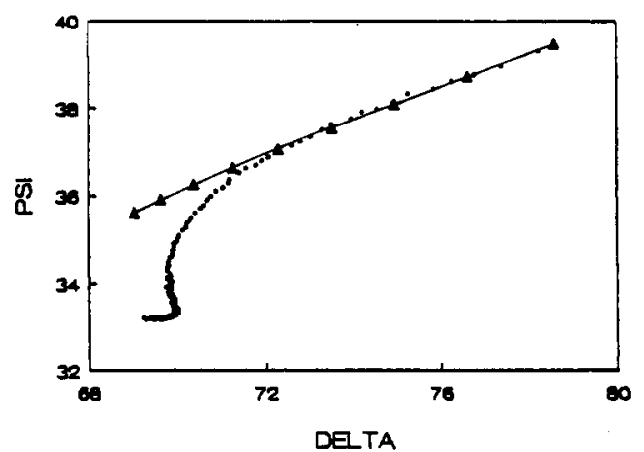

Fig. 12. Change of $\Psi-\Delta$ during deposition of $\mathrm{Bi}$ on $\mathrm{Au}$ at $i=0.1 \mathrm{~mA} \mathrm{~cm}{ }^{-2}$; electrolyte, $1 \mathrm{M} \mathrm{HClO}_{4}+2 \mathrm{mM}$ $\mathrm{Bi}\left(\mathrm{NO}_{3}\right)_{3}$; wavelength, $546.1 \mathrm{~nm}$. Full line: calculated for film growth with $n=1.18 ; k=1.85$; (A) points indicate thickness increase of $30 \AA$.

\section{SUMMARY}

Optical monitoring of upd is possible if the refractive index of the layer differs from the substrate. Ellipsometric changes were observed for upd of $\mathrm{Bi}$ on $\mathrm{Au}$ and for $\mathrm{Ge}$ on $\mathrm{Pt}$, for $\mathrm{Cu}$ on $\mathrm{Au}$ a marginal change was seen; upd of $\mathrm{Bi}$ on $\mathrm{Pd}$ and $\mathrm{Pt}$ does not give rise to an optical change. The start of bulk deposition of $\mathrm{Cu}$ on $\mathrm{Au}$ and of $\mathrm{Bi}$ on $\mathrm{Au}$ was found to proceed at constant refractive index; due to the presence of the upd layer, sufficient nuclei have been created to enable homogenous growth.

\section{REFERENCES}

1. D. Kolb, in Advances in Electrochemistry and Electrochemical Engineering (Edited by $\mathrm{H}$. Gerischer and $\mathrm{Ch}$. W. Tobias), Vol. 11, p. 125, Wiley, New York (1978).

2. K. Jüttner, Electrochim. Acta 31, 917 (1986)

3. K. Jüttner and W. Lorenz, $Z$. phys. Chem. NF 122, 163 (1980).

4. R. R. Adzic, in Advances in Electrochemistry and Engineering (Edited by H. Gerischer), Vol. 13, p. 159, Wiley, New York (1984).

5. G. Kokkinidis, J. electroanal. Chem. 201, 217 (1986).

6. H. Bort, K. Jüttner, W. J. Lorenz, G. Staikov and E. Budevski, Electrochim. Acta 28, 985 (1983).

7. M. Shibata and S. Motoo, J. electroanal. Chem. 202 , 137 (1986).

8. S. M. Sayed and K. Jüttner, Electrochim. Acta 28, 1635 (1983).

9. K. Takamura, F. Watanabe and T. Takamura, Electrochim. Acta 26, 979 (1981).

10. J. Horkans, B. D. Cahan and E. Yeager, J. electrochem. Soc. 122, 1585 (1975)

11. W. Visscher, Electrochim. Acta 34, 1169 (1989).

12. S. H. Cadle and S. Bruckenstein, Anal. Chem. 44, 1993 (1972).

13. R. R. Adzic, D. N. Simic, A. R. Despic and D. M Drazic, J. electroanal. Chem. 65, 587 (1975).

14. N. Furuya and S. Motoo, J. electroanal. Chem. 99, 19 (1979).

15. W. J. Lorenz, I. Moumtzis and E. Schmidt, J. electroanal. Chem. 33, 121 (1971).

16. T. Takamura, Y. Sato and $\mathrm{K}$. Takamura, J. electroanal. Chem. 41, 31 (1973).

17. American Institute of Physics Handbook, 3rd edn, pp. 6-114 (1972). 